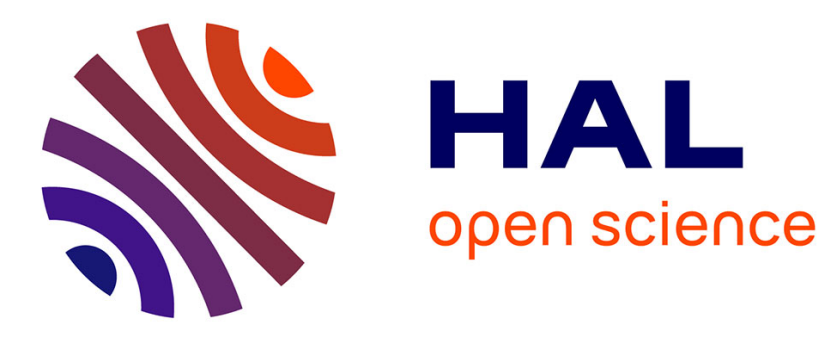

\title{
A Novel Classification of 3D Rib Cage Deformity in Subjects With Adolescent Idiopathic Scoliosis
}

Ayman Assi, Mohamad Karam, Wafa Skalli, Claudio Vergari, Raphael Vialle, Raphael Pietton, Aren J. Bizdikian, Khalil Kharrat, Jean Dubousset, Ismat Ghanem

\section{To cite this version:}

Ayman Assi, Mohamad Karam, Wafa Skalli, Claudio Vergari, Raphael Vialle, et al.. A Novel Classification of 3D Rib Cage Deformity in Subjects With Adolescent Idiopathic Scoliosis. Clinical Spine Surgery, 2021, pp.1-11. 10.1097/bsd.0000000000001139 . hal-03163163

\section{HAL Id: hal-03163163 https://hal.science/hal-03163163}

Submitted on 9 Mar 2021

HAL is a multi-disciplinary open access archive for the deposit and dissemination of scientific research documents, whether they are published or not. The documents may come from teaching and research institutions in France or abroad, or from public or private research centers.
L'archive ouverte pluridisciplinaire HAL, est destinée au dépôt et à la diffusion de documents scientifiques de niveau recherche, publiés ou non, émanant des établissements d'enseignement et de recherche français ou étrangers, des laboratoires publics ou privés. 


\title{
A Novel Classification of 3D Rib Cage Deformity in Subjects With Adolescent Idiopathic Scoliosis
}

\author{
Ayman Assi, PhD, ${ }^{* \dagger}$ Mohamad Karam, MSc, ${ }^{*}$ Wafa Skalli, PhD, $\dagger$ Claudio Vergari, PhD, $\dagger$ \\ Raphael Vialle, MD, PhD, $\neq$ Raphael Pietton, MD, PhD, $\neq$ Aren J. Bizdikian, MD, MSc,* \\ Khalil Kharrat, MD, * Jean Dubousset, MD, PhD, $\dagger$ and Ismat Ghanem, MD, MSc*
}

Study Design: This was a multicentric cross-sectional descriptive study.

Objective: To analyze patterns of 3D rib cage deformity in subjects with adolescent idiopathic scoliosis (AIS) and their relationship with the spinal deformity.

Summary of Background Data: Subjects with AIS present with rib cage deformity that can affect respiratory functions. The $3 \mathrm{D}$ rib cage deformities in AIS and their relationship to the spinal deformity are still unelucidated.

Methods: A total of 200 AIS and 71 controls underwent low-dose biplanar x-rays and had their spine and rib cage reconstructed in 3-dimensional (D). Classic spinopelvic parameters were calculated in 3D and: rib cage gibbosity, thickness, width, volume and volumetric spinal penetration index (VSPI). Subjects with AIS were classified as: group I with mild rib cage deformity $(n=88)$, group II with severe rib cage deformity $(n=112)$ subgrouped into IIa (high gibbosity, $n=48$ ), IIb (high VSPI, $n=48$ ), and IIc (both high gibbosity and VSPI, $\mathrm{n}=16$ ).

Results: Groups IIa and IIb had a higher Cobb angle (33 vs. 54 degrees and 46 degrees, respectively) and torsion index (11 vs. 14 degrees and 13 degrees, respectively) than group I. Group IIb showed more severe hypokyphosis ( $\mathrm{IIb}=21$ degrees; IIa $=33$ degrees; $\mathrm{I}=36$ degrees; control $=42$ degrees) with a reduced rib cage volume $(\mathrm{IIb}=$ $4731 \mathrm{~cm}^{3} ; \quad$ IIa $=4985 \mathrm{~cm}^{3} ; \quad I=5257 \mathrm{~cm}^{3} ; \quad$ control $\left.=5254 \mathrm{~cm}^{3}\right)$ and thickness $(\mathrm{IIb}=135 \mathrm{~mm}$; IIa $=148 \mathrm{~mm} ; \mathrm{I}=144 \mathrm{~mm}$; control $=144$ $\mathrm{mm})$. Group IIa showed an increasingly large local gibbosity descending from proximal to distal levels and did not follow the axial rotation of the spine. Group IIc showed characteristics of both groups IIa and IIb.

Received for publication July 29, 2020; accepted December 22, 2020.

From the *Faculty of Medicine, University of Saint-Joseph in Beirut, Beirut, Lebanon; †Institut de Biomécanique Humaine Georges Charpak, Arts et Métiers ParisTech; and \$Department of Pediatric Orthopedics, Armand Trousseau Hospital, Université Pierre et Marie Curie-Paris 6, Paris, France.

This research was funded by the University of Saint-Joseph (grant FM312). The funding sources did not intervene in study design; in the collection, analysis and interpretation of data; in the writing of the report; and in the decision to submit the article for publication.

The authors declare no conflict of interest.

Reprints: Ayman Assi, PhD, Laboratory of Biomechanics and Medical Imaging, Faculty of Medicine, University of Saint-Joseph, Damascus Street, PO Box 17-5208, Mar Mekhaël, Beirut 1104 2020, Lebanon (e-mails: ayman.assi@usj.edu.lb; ayman.assi@gmail.com).

Copyright (C) 2021 Wolters Kluwer Health, Inc. All rights reserved.
Conclusions: This new classification of 3D rib cage deformity in AIS shows that the management of cases with high VSPI (groups $\mathrm{IIb}$ and IIc) should focus on restoring as much kyphosis as possible to avoid respiratory repercussions. Treatment indications in groups I and IIa would follow the consensual basic principles reported in the literature regarding bracing and surgery.

Key Words: adolescent idiopathic scoliosis, rib cage, spine, rib hump, gibbosity, penetration index

$A$ dolescent idiopathic scoliosis (AIS) is a public health issue affecting the self-image and quality of life of patients and their families, ${ }^{1-6}$ along with the presence of associated cardiac abnormalities. $^{7}$ A difficult journey begins after diagnosis, requiring many clinical and radiologic follow-ups accompanying these patients into adulthood and beyond, ${ }^{8}$ leading to increased rates of cancer in this population. ${ }^{9,10}$ In addition, these patients are known to develop restricted pulmonary function, a direct result of their spinal deformity. ${ }^{11-13}$ Most patients usually end up requiring either corrective braces or spinal surgery which further compile onto the socioeconomic burden of this disease. $^{14,15}$

AIS is a complex deformity of the spine involving all 3-dimensions (D). In the frontal plane, the spine is usually deviated, giving a C-shaped or S-shaped appearance and the severity of the deformity is generally assessed using the Cobb angle. ${ }^{16}$ In the sagittal plane, the back is flattened, a process known as hypokyphosis. ${ }^{17}$ In the horizontal plane, the vertebrae are rotated, and the maximal rotation generally appears at the level of the apical vertebra. ${ }^{18}$

This 3D deformity directly influences the chest wall through the costo-vertebral joints and leads to rib cage asymmetry, which in turn produces a gibbus, or rib hump. This gibbosity, often regarded as the fourth-dimension of scoliotic deformity, ${ }^{19-21}$ was shown to be directly related to the Cobb angle ${ }^{22}$ and was found to be the second most frequently cited factor leading patients to seek surgical treatment due to its esthetically unpleasant nature. ${ }^{2}$

Another parameter, first described by Dubousset et $\mathrm{al}^{23}$ for the assessment of the rib cage in subjects with neuromuscular diseases with severe thoracic lordoscoliosis, known as the volumetric spinal penetration index (VSPI), was later adapted for use in subjects with AIS. 
This VSPI is defined as the percentage of rib cage volume occupied by the penetration of the spine and reflects the functional space available for the lungs: the higher the VSPI, the more likely it is for the scoliotic deformity to produce respiratory impairment. Moreover, progressive scoliosis and rib cage asymmetry are known to be associated with chest wall and diaphragmatic mechanical dysfunctions leading to respiratory impairment. ${ }^{11-13,24}$

Many methods have been described for the assessment of rib cage morphology, including 2D and 3D imaging modalities. ${ }^{25}$ Frontal and sagittal 2D radiographs have shown limitations in the estimation of the horizontal deformity and lack in precision. A 3D reconstructions based on computerized tomography scans, even though considered as the gold standard in 3D evaluation of the rib cage, are not recommended due to high radiation doses and the supine position during acquisitions which may reduce the severity of some deformities when freed from the effects of gravity. ${ }^{26}$ Recently, a new technique using low-dose biplanar x-rays acquired in the free-standing position has shown its efficacy in calculating the 3D deformity of the rib cage with high validity ${ }^{27,28}$ and reliability. ${ }^{29}$ This new technique can be useful in the assessment of rib cage deformities in subjects with AIS and their relationship with the scoliotic spinal deformity.

Our first hypothesis was that the severity of the spinal deformity as measured by the Cobb angle is not the only factor affecting the space available for the lungs. The second hypothesis was that more than 1 pattern of rib cage deformity is associated with thoracic AIS. The purpose of this study was to validate these 2 hypotheses.

\section{METHODS}

This is a multicentric IRB approved (CEHDF742) cross-sectional descriptive study of nonoperated subjects with AIS who had previously consulted for radiographic follow-up. Data were collected from 3 different centers. Nonscoliotic control subjects formerly recruited for previous studies were also included. Written and informed consent was obtained from all subjects and their legal guardians.

In the case of subjects with AIS, inclusion criteria were: ages 10 to 18 years, and frontal Cobb angle $\geq 10$ degrees; exclusion criteria were: congenital or neurological scoliosis, infantile and juvenile scoliosis, structural leg length discrepancy $\geq 1 \mathrm{~cm}$, and a scoliotic deformity with only a single major curve located at the lumbar or thoracolumbar regions (Lenke-5). Since subjects with Lenke-6 include both a main thoracic and thoracolumbar/lumbar structural curve, these subjects were included while accounting for the thoracic scoliotic curve.

In the case of controls, inclusion criteria were: ages 10 and 18 years, and no known underlying musculoskeletal or neurological disorders; the exclusion criterion was a frontal Cobb angle $>10$ degrees.

Demographic data (age, weight, height, and sex) were collected for all subjects in both groups.

\section{Data Acquisition}

All subjects underwent full-body low-dose biplanar $\mathrm{x}$-rays (EOS Imaging, Paris, France). Subjects were placed in the free-standing position. ${ }^{30,31} 3 \mathrm{D}$ reconstructions of their spines and rib cages were undertaken by trained operators using the dedicated SterEOS software (version 1.8.99.20R; EOS Imaging, Paris, France). These reconstructions were then processed using previously validated methods, ${ }^{32,33}$ from which $3 \mathrm{D}$ rib cage, spinopelvic and scoliosis parameters were extracted.

Rib cage parameters included (Fig. 1):

- thickness (mm): maximum antero-posterior distance between the most posterior point of the rib cage and its projection on the sternal vertical axis,

- width $(\mathrm{mm})$ : maximum frontal width of the rib cage,

- volume $\left(\mathrm{cm}^{3}\right)$ : integration of different layered surfaces extracted from rib cage reconstructions, ${ }^{29}$

- gibbosity (degree): angle between the horizontal axis and the axis passing through the most posterior prominent points on both sides of the rib cage, ${ }^{27}$

- local gibbosity (degree) at each vertebral level from T1 to T10, and

- VSPI (\%): ratio of the spinal volume penetrating the chest to the rib cage volume. ${ }^{23}$

The validity and reliability of these parameters have already been evaluated in previous studies. ${ }^{27,29,34}$

Spinopelvic parameters were (Fig. 2): T1T12 kyphosis (degree), T4T12 kyphosis (degree), T10L2 thoracolumbar junction angle (negative values indicate kyphosis) (degree), L1S1 lordosis (LL) (degree), frontal Cobb angle (degree), apical vertebral rotation (degree), vertebral axial rotation from $\mathrm{T} 1$ to $\mathrm{T} 10$ (degree), torsion index (TI in degree, as the mean sum of the intervertebral axial rotations from the lower end vertebra to the apex and from apex to the upper end vertebra), pelvic incidence (PI) (degree), sacral slope (SS) (degree), and pelvic tilt (PT) (degree). The relationship between SS and LL was presented as a scatter plot as suggested by Legaye and Duval-Beaupère. ${ }^{35}$

\section{Subject Classification}

Subjects with AIS were grouped according to gibbosity and VSPI. Subjects with normal or slightly elevated gibbosity and VSPI, but lower than the 95th percentile of the control values, were grouped as mild rib cage deformity (group I). The remaining subjects who presented a high gibbosity and/or VSPI, greater than the 95th percentile of control values, were grouped as severe rib cage deformity (group II) and further divided into 3 subgroups: only high gibbosity (group IIa), only high VSPI (group IIb), and both high gibbosity and VSPI (group IIc).

The distribution of patients according to the Lenke classification $^{36}$ and the Abelin-Genevois sagittal classification ${ }^{37}$ was then characterized in each rib cage deformity group. The structural scoliotic curve was defined as major thoracic (Lenke1), double curvatures (Lenke-2, 3, 6) or triple major (Lenke-4). Abelin-Genevois types were: AG-1: normal sagittal shape; type AG-2a: thoracic hypokyphosis with cervical kyphosis (3 alternating sagittal curves); type AG-2b: thoracic hypokyphosis and thoracolumbar kyphosis (4 alternating sagittal curves); Type AG-3: proximal cervicothoracic kyphosis and a long thoracolumbar lordosis (only 2 alternating sagittal curves). 


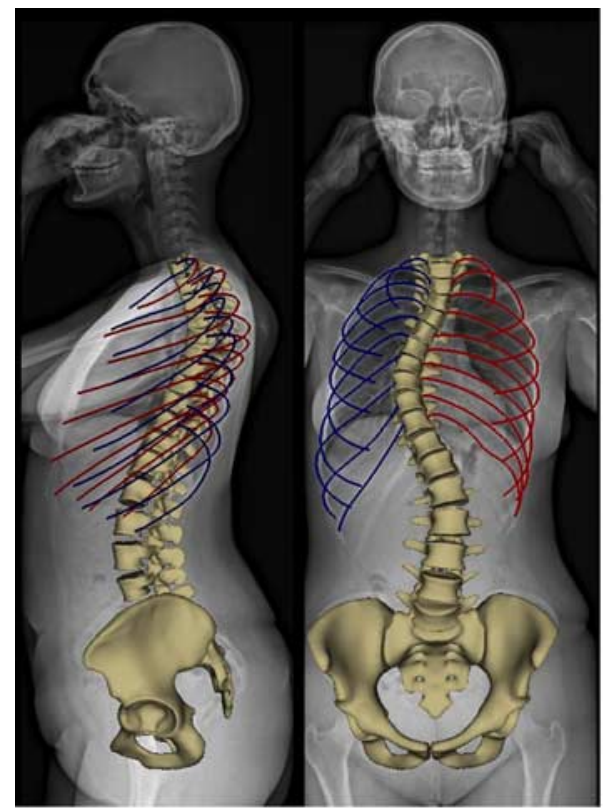

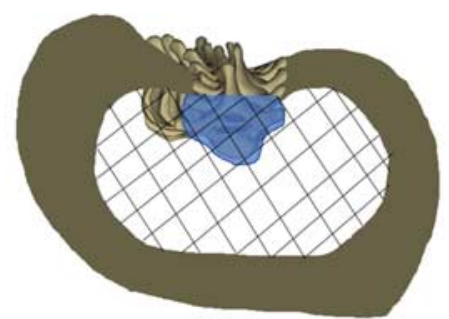

Volumetric spinal penetration index

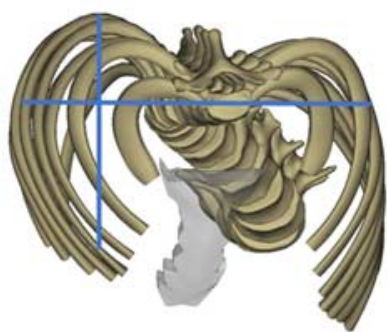

Maximum thickness \& width

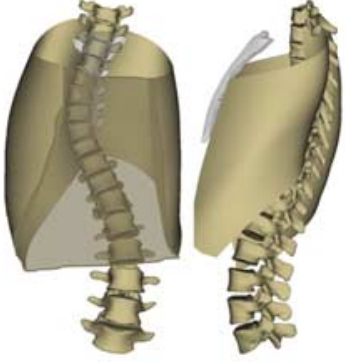

Rib cage volume

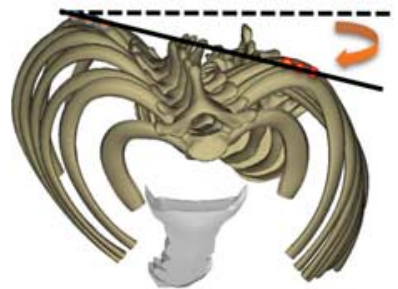

Gibbosity

FIGURE 1. Biplanar x-rays and 3D reconstruction of the spine, pelvis and the rib cage along with the calculated parameters on the rib cage reconstructions: volumetric spinal penetration index (blue area), rib cage volume, maximum thickness and width, and gibbosity. $\frac{\text { full color }}{\operatorname{lnl} \operatorname{lin} \mathrm{e}}$

\section{Statistical Analysis}

Differences in age, weight, and height between subjects with AIS and controls were investigated using either a Mann-Whitney $U$ test or a Student $t$ test depending on
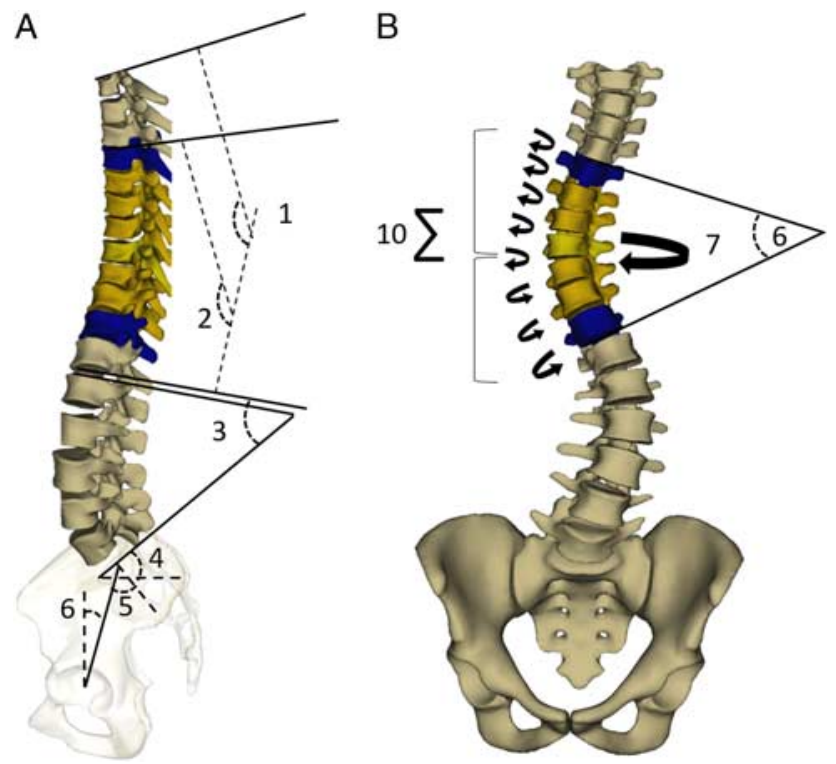

FIGURE 2. Spinopelvic and scoliosis parameters calculated on 3D reconstructions: $A$, (1) T1T12 kyphosis; (2) T4T12 kyphosis; (3) L1S1 lordosis; (4) sacral slope (SS); (5) pelvic incidence (PI) and (6) pelvic tilt (PT). B, (6) frontal Cobb angle; (7) apical vertebral rotation (AVR and 10) Torsion index (TI): defined as the mean of the sum of intervertebral axial rotations from lower junction to apex and from apex to upper junction. full color the normality of the data (Shapiro-Wilk test). The distribution of sex was compared between groups using $\chi^{2}$ test.

Differences in rib cage, spinopelvic and scoliosis parameters were investigated between controls and AIS in the different groups of rib cage classification; either a KruskalWallis test or analysis of variance model, followed by pairwise comparisons and Bonferroni corrections, were computed depending on the normality of the data.

Relationships between the rib cage deformity (gibbosity and VSPI) in group II and the 3D spinal deformity (frontal plane: Cobb angle, sagittal plane: T1T12, and horizontal plane: TI) were investigated using a Pearson correlation test. The relationship between the vertebral axial rotation and the local gibbosity at the level of the apical vertebra and its 2 adjacent units proximally and distally was also evaluated.

The level of significance for all statistical tests was set at 0.05 . Statistics were performed using Xlstat (version 2019.1.2; Addinsft, Paris, France).

\section{RESULTS}

\section{Sample Description}

A total of 200 subjects with AIS [166 females; frontal Cobb angle: $43 \pm 23$ degrees (10-128 degrees)] and 71 controls (51 females) were included. Demographic parameters did not differ between groups (all $P>0.05$, Table 1). The distributions of subjects with AIS according to Lenke and Abelin-Genevois were presented in Table 2.

The control group allowed for the definition of the threshold of high gibbosity ( $>9$ degrees) and VSPI 
TABLE 1. Comparison of Demographic Parameters Between Controls and the Adolescent Idiopathic Scoliosis (AIS) Population

\begin{tabular}{lccc}
\hline & \multicolumn{3}{c}{ Mean (SD) } \\
\cline { 2 - 3 } Demographics & Controls (n= 71) & Subjects With AIS (n= 200) & $\boldsymbol{P}$ \\
\hline Age (y) & $14(3)$ & $14(2)$ & 0.27 \\
Weight $(\mathrm{kg})$ & $54(14)$ & $53(9)$ & 0.56 \\
Height $(\mathrm{cm})$ & $156(12)$ & $155(11)$ & 0.50 \\
Sex & & & \\
F & 51 & 166 & 0.07 \\
M & 19 & 34 & \\
\hline
\end{tabular}

( $>6.3 \%$ ) according to the 95th percentile. As for the novel rib cage deformity classification, $44 \%(n=88)$ of AIS had both normal or subnormal gibbosity and VSPI and were classified as group I with mild rib cage deformity; 24\% $(n=48)$ of AIS had only a high gibbosity and were classified as group IIa; $24 \%(\mathrm{n}=48)$ of AIS had only a high VSPI and were classified as group IIb; the remaining $8 \%$ $(\mathrm{n}=16)$ of AIS had both high gibbosity and VSPI and were classified as group IIc. In total, $56 \%(n=112)$ of subjects with AIS were classified as group II with severe rib cage deformity.

Most subjects in group II had mainly major thoracic curves (Lenke-1), independently from the sub-groups (group IIa $=77 \%$, group IIb $=65 \%$, and group IIc $=88 \%$ ). Subjects in groups IIa and IIc were essentially classified as types AG-1 and AG-2a (Table 2).

\section{Rib Cage Parameters}

Subjects in group II had smaller rib cage volumes compared with group I and controls $(P=0.008)$ and higher gibbosity and VSPI $(P<0.001)$ (Fig. 3).

Subjects in group IIb showed decreased thickness and higher VSPI compared with groups I, IIa, and controls (thickness: 135 vs. $144 \mathrm{~mm}$ vs. 148 and $144 \mathrm{~mm}$, respectively, $P=0.002$; VSPI: $7 \%$ vs. $5 \%$ vs. $5 \%$ and $4 \%$, respectively, $P<0.001$, Table 3 ). Rib cage volume was significantly lower in group IIb compared with group I (4731 vs. $5257 \mathrm{~cm}^{3}$, $P=0.01)$. In addition, gibbosity was significantly higher in group IIa compared with groups I, IIb, and controls (15 vs. 5 degrees vs. 6 and 4 degrees, respectively). Subjects in group IIc had higher gibbosity than group IIb and higher VSPI than group IIa (Table 3, Fig. 3).

\section{Spinopelvic and Scoliosis Parameters}

Subjects with severe rib cage deformity (group II) showed lower kyphosis than group I and controls (28 vs. 36 degrees and 42 degrees, respectively, $P<0.001$ ), and a higher T10L2, TI, frontal Cobb angle, SS, and PI than group I and controls. LL was comparable between groups although the SS was significantly different (Fig. 4). In order to better investigate the spinopelvic alignment in group II, the interaction between LL and $\mathrm{SS}^{35}$ was plotted (Fig. 5). In controls, an SS of 39 degrees induced an LL of 58 degrees. However, an SS of 45 degrees in group II induced an LL of 59 degrees, a loss of 11 degrees of LL relative to its theoretical value according to normative spinopelvic alignment.

When analyzing subgroups in subjects with severe rib cage deformity (group II), subjects in group IIb with high VSPI showed lower kyphosis when compared with groups I, IIa and (ie, T1T12: 21 vs. 36 degrees vs. 33 and 42 degrees, respectively, $P<0.001)$. Subjects in group IIc had a similar sagittal profile to groups IIa and IIb, and a more severe scoliotic deformity in the frontal and horizontal planes (Table 3, Fig. 4).

\section{Relationship Between Rib Cage Deformity and Spinopelvic Parameters}

The VSPI was negatively correlated to T1T12 $(r=-0.47, P<0.001)$ in all subjects in group II (Fig. 6A). Gibbosity was positively correlated to the frontal Cobb angle $(r=0.54, P<0.001)$ and TI $(r=0.41, P<0.001)$ in groups IIa and IIc, but not in group IIb (Figs. 6B, C).

In subjects in group IIa, vertebral axial rotation and local gibbosity increased simultaneously from the proximal adjacent units until reaching the apex (Fig. 7); while the vertebral axial rotation started to decrease when descending distally, the local gibbosity continued to increase. In subjects in group IIb, the vertebral axial rotation had a similar

TABLE 2. Classification of Subjects With Adolescent Idiopathic Scoliosis (AIS) and Groups and Subroups of Rib Cage Deformity According to Lenke and Abelin-Genevois

\begin{tabular}{|c|c|c|c|c|c|c|c|c|}
\hline \multirow[b]{2}{*}{ Groups } & \multicolumn{4}{|c|}{ Lenke Classification } & \multicolumn{4}{|c|}{ Abelin-Genevois Sagittal Classification } \\
\hline & Lenke 1 & Lenke 2 & Lenke 3 & Lenke 6 & AG-1 & AG-2a & AG-2b & AG-3 \\
\hline $\begin{array}{l}\text { Total sample of subjects with AIS } \\
(\mathrm{n}=200)\end{array}$ & $66 \% ; n=131$ & $5 \% ; n=10$ & $19 \% ; n=38$ & $11 \% ; n=21$ & $52 \% ; \mathrm{n}=103$ & $22 \% ; n=44$ & $13 \% ; n=26$ & $14 \% ; n=27$ \\
\hline \multicolumn{9}{|l|}{ Rib cage deformity 3D classification } \\
\hline $\begin{array}{l}\text { Group I: mild rib cage deformity } \\
(44 \% ; n=88)\end{array}$ & $56 \% ; n=49$ & $5 \% ; n=4$ & $24 \% ; n=21$ & $16 \% ; n=14$ & $63 \% ; n=55$ & $10 \% ; n=9$ & $3 \% ; n=3$ & $24 \% ; n=21$ \\
\hline $\begin{array}{l}\text { Group II: severe rib cage deformity } \\
\quad(56 \% ; \mathrm{n}=112)\end{array}$ & $73 \% ; n=82$ & $5 \% ; n=6$ & $15 \% ; n=17$ & $6 \% ; n=7$ & $43 \% ; n=48$ & $31 \% ; n=35$ & $21 \% ; n=23$ & $5 \% ; n=6$ \\
\hline $\begin{array}{l}\text { Group IIb: high VSPI } \\
(24 \% ; n=48)\end{array}$ & $65 \% ; n=31$ & $8 \% ; n=4$ & $17 \% ; n=8$ & $10 \% ; n=5$ & $27 \% ; n=13$ & $33 \% ; n=16$ & $35 \% ; n=17$ & $4 \% ; n=2$ \\
\hline $\begin{array}{l}\text { Group IIc: high gibbosity } \\
\& \text { VSPI }(8 \% ; n=16)\end{array}$ & $88 \% ; \mathrm{n}=14$ & $6 \% ; n=1$ & $6 \% ; n=1$ & 0 & $56 \% ; n=9$ & $25 \% ; n=4$ & $13 \% ; n=2$ & $6 \% ; n=1$ \\
\hline
\end{tabular}



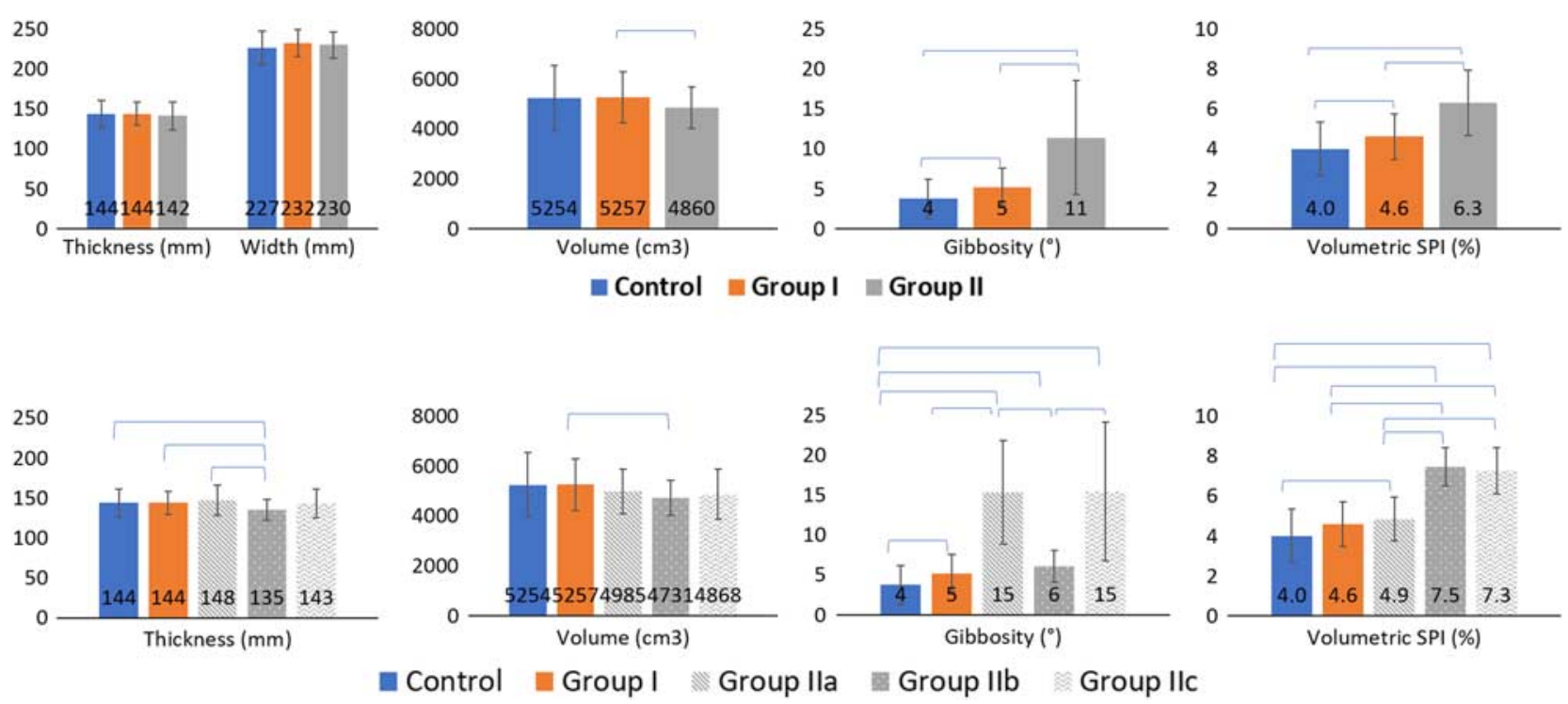

FIGURE 3. Comparisons of rib cage parameters between groups and subgroups. Blue brackets indicate statistically significant difference $(P<0.005)$. full color

pattern to that in group IIa, but local gibbosity remained constant throughout.

\section{DISCUSSION}

Subjects with AIS usually present with thoracic asymmetry, a deformity known as gibbosity, ${ }^{38}$ a true esthetic inconvenience; this gibbosity is due to the synergy between the spinal deformity and the rib cage at the level of the costo-vertebral joints. ${ }^{20,21}$ Thoracic scoliosis is generally associated with hypokyphosis resulting in the spine to penetrate inside the rib cage. ${ }^{23}$ This study investigated rib cage deformities in 200 subjects with AIS for which the spines and the rib cages were reconstructed in 3D using a novel technique based on low-dose biplanar x-raysu. ${ }^{27}$ We identified 4 groups of rib cage deformity patterns in AIS: group I with mild rib cage deformity; group II with severe rib cage deformity, further stratified into group IIa with high gibbosity, group IIb with high VSPI, and group IIc with both high gibbosity and VSPI.

Subjects in this study had mainly a single major thoracic curve (66\%), which was concordant with the literature, ${ }^{39,40}$ and were mostly classified as Type AG-1 (52\%) according to the Abelin-Genevois sagittal classification.

\section{Patterns of Subjects With Mild Rib Cage Deformity-Group I}

Subjects in group I presented a higher gibbosity and VSPI than controls without exceeding clinical significance; their rib cage volume remained similar. While remaining in the 95th percentile corridor of normality, some subjects had their gibbosity and VSPI shifted upwards. Subjects in group I showed decreased kyphosis compared with controls, a higher torsion index and a moderate Cobb angle. This shows that, despite the altered 3D spinal deformity, there were no modifications in rib cage volume, as suggested in a previous study. ${ }^{4}$

\section{Patterns of Subjects With Severe Rib Cage Deformity-Group II}

Subjects in group II showed a reduced rib cage volume compared with subjects in group I. Moreover, the most severe 3D spinal deformities were found in this group (hypokyphosis, higher TI, and Cobb angle). Subjects in group II presented with a higher PI and SS than in controls. Moreover, SS, PI, and PT are inter-related $(\mathrm{PI}=\mathrm{SS}$ $+\mathrm{PT})^{42}$ and SS has a major influence on lumbar lordosis. ${ }^{43}$ While the SS was higher in group II, the PT was surprisingly similar between groups I, II, and controls. Thus, subjects in group II presented, in addition to severe rib cage deformities (high gibbosity and VSPI, and low rib cage volume), an altered sagittal alignment with thoracic hypokyphosis, a lordotic thoracolumbar junction, high PI and SS, and reduced LL relative to expected values. These differences between groups were maintained even when controlling for PI during statistical analysis.

\section{Specific Patterns in Subgroups of Subjects With Severe Rib Cage Deformity-Groups Ila, IIb, Ilc}

When further investigating subgroups within group II, group IIc presented the most severe scoliotic deformity in the frontal and horizontal planes, and group IIb presented a significantly reduced rib cage thickness and volume when compared with other subjects. Furthermore, subjects in this group presented a greater loss of kyphosis compared with subjects in groups I, IIa, and controls. This hypokyphosis might have forced the rib cage to move anteriorly, thereby decreasing the gibbosity. This finding is supported by the fact that a high number of patients in group IIb were classified as type AG-2a (33\%) or AG-2b $(35 \%)$ of the Abelin-Genevois sagittal classification, both of which are characterized by a hypokyphotic thoracic spine. Moreover, subjects in all 3 subgroups of group II showed negative correlations between their thoracic kyphosis and 
TABLE 3. Comparison of Spinopelvic, Scoliosis and Rib Cage Parameters Between Controls and Sub-groups of Subjects With Adolescent Idiopathic Scoliosis (AIS) Classified According to Severity of Rib Cage Deformity

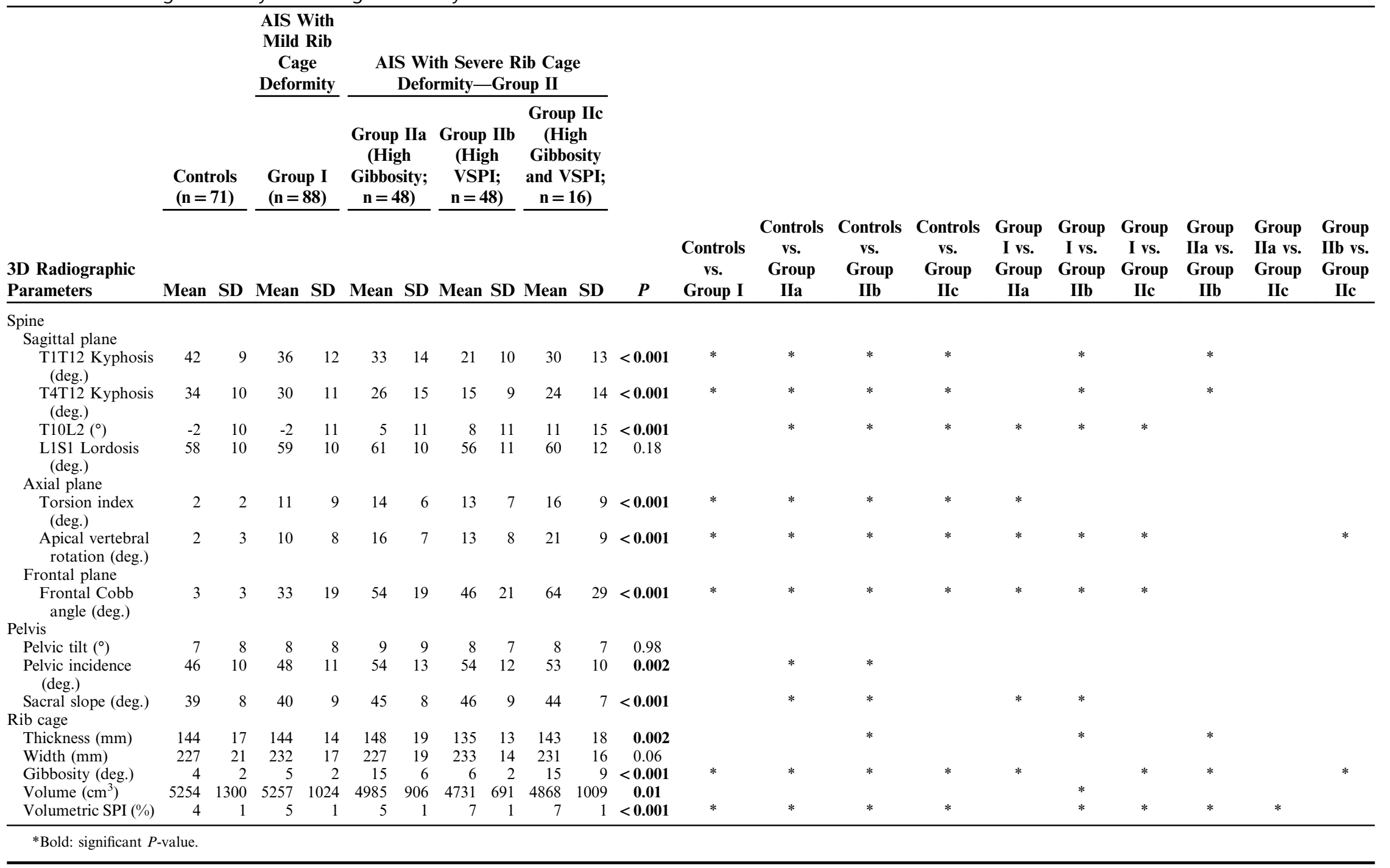



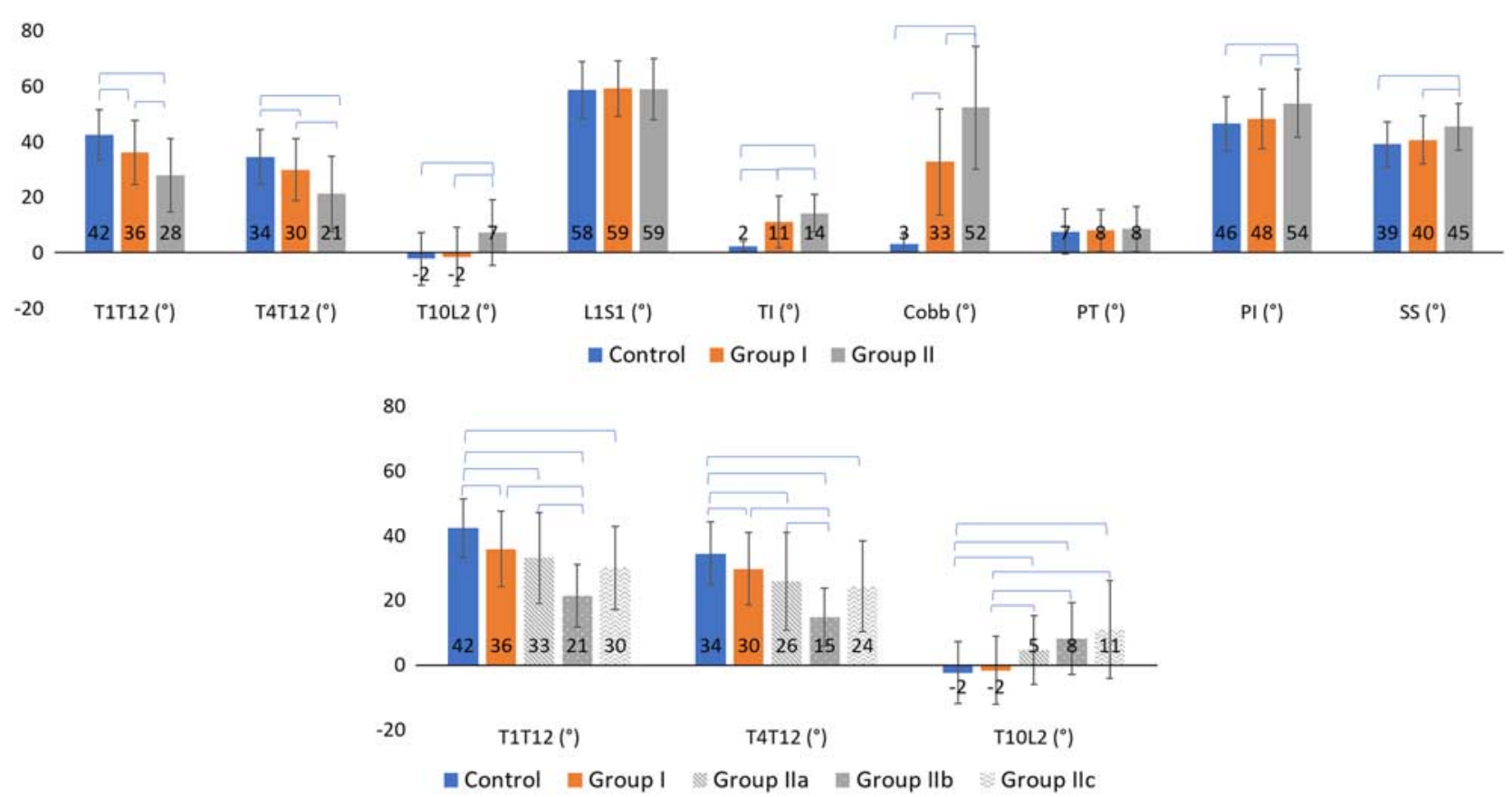

FIGURE 4. Comparisons of spinopelvic and scoliosis parameters between groups and subgroups. Blue brackets indicate statistically significant difference $(P<0.005)$. $\frac{\text { full color }}{0 \text { l line }}$

VSPI, showing that the increased penetration of the spine within the rib cage might be a result of flat backs. In fact, the sagittal flattening of the spine is known to reduce rib cage volume and cause respiratory impairment. ${ }^{44,45}$

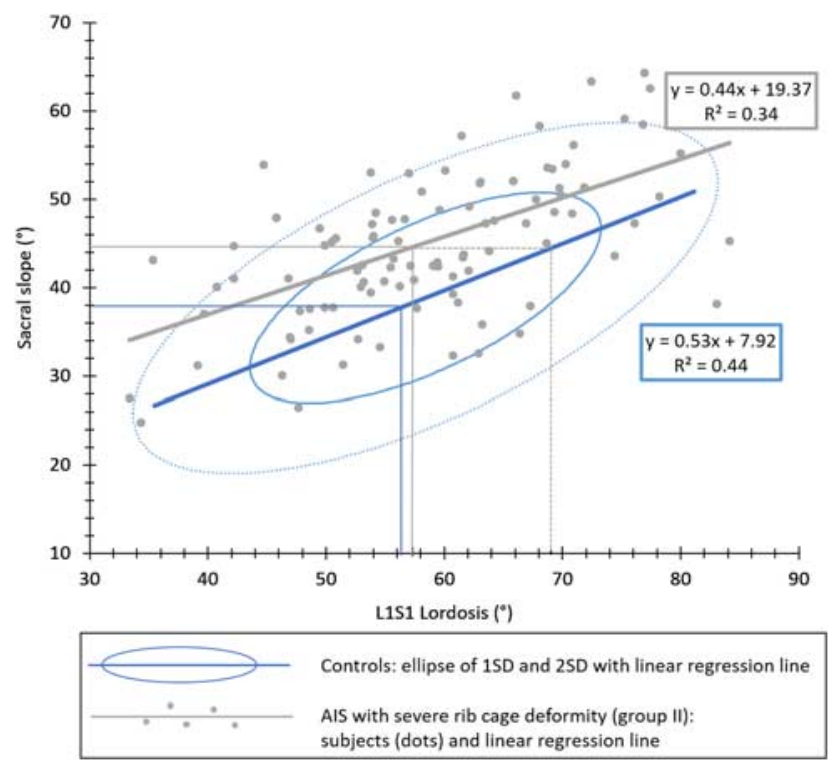

FIGURE 5. Spinopelvic sagittal malalignment in adolescent idiopathic scoliosis (AIS) with severe rib cage deformity compared with controls. Blue ellipses at 1 SD and 2 SD of control subjects. Subjects with AIS with severe rib cage deformity (group II) are presented in gray dots and lines. Mean values and expected means were plotted. full color
The relationship between the vertebral axial rotation and the local gibbosity at the level of the scoliotic segment presented a specific pattern for subjects in group IIb. While the vertebral axial rotation increased when descending from the proximal adjacent vertebrae toward the apex and decreased once again when moving distally, the local gibbosity was almost unchanged at all levels, showing a decoupling between vertebral axial rotation and local gibbosity.

Furthermore, even though subjects in group IIa were described as having only a high gibbosity, they nonetheless presented with a significantly higher VSPI than controls, without any loss in thickness or volume. Furthermore, most of these subjects presented a different sagittal profile than subjects in group IIb and were classified as type AG-1 (54\%) (Fig. 8), compared with group IIb, who were mostly classified as types AG-2a (33\%) and AG-2b (35\%). This further stresses the fundamental differences between these groups.

This study also showed that, in subjects in group IIa, the gibbosity increased simultaneously not only with the frontal Cobb angle, as has previously been shown, ${ }^{11}$ but also with the TI. Moreover, vertebral axial rotation and local gibbosity were shown to increase simultaneously when descending from the proximal adjacent units toward the apex (Fig. 7). While the vertebral axial rotation decreased once again when moving distally, the local gibbosity maintained its elevation. This pattern was strikingly different from that seen in group IIb, where the gibbosity remained low independently from the axial vertebral rotation.

This study showed that the frontal Cobb angle is not the sole predictor of rib cage deformity since thoracic 

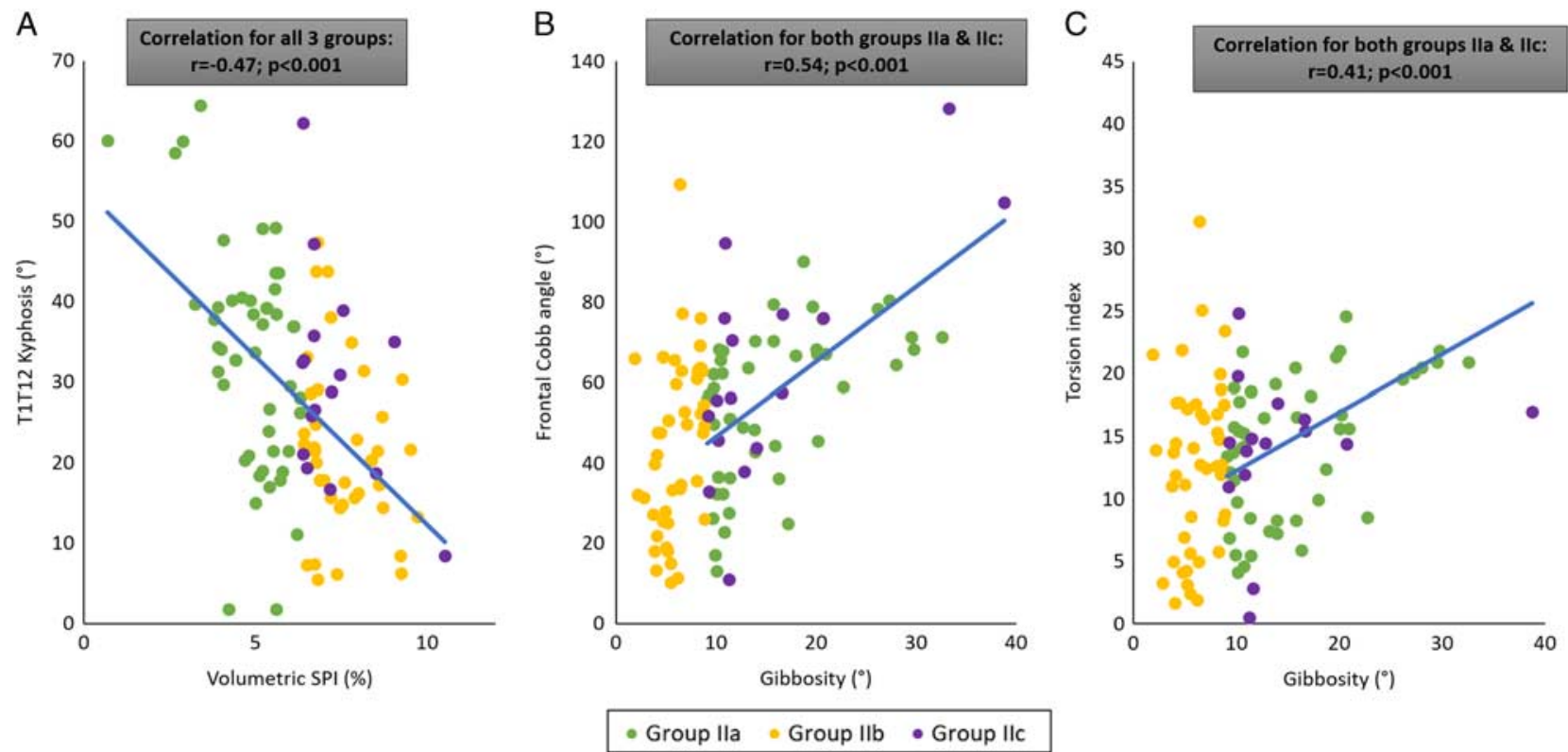

FIGURE 6. Correlation between rib cage deformity and spinopelvic parameters in group II. full color

hypokyphosis and TI showed equally strong correlations to VSPI and gibbosity, respectively.

The major limitation of this study is related to the lack of functional lung assessments (in the form of pulmonary function tests or spirometry). Thus, it would be interesting to compare lung assessment results between groups of 3D rib cage deformity. However, previous studies have shown that the reduced rib cage volume was a strong predictor of impaired pulmonary function. ${ }^{11}$
In summary, subjects in groups IIa and IIb showed more severe frontal and axial spinal deformities (Fig. 8). When compared with group I, they showed a higher PI and SS while maintaining a similar PT. This was associated with thoracic hypokyphosis and a lower LL than was expected for such spinopelvic alignment.

Subjects in group IIb showed a more severe hypokyphosis with a reduced rib cage volume and thickness. In group IIa, the local gibbosity increased progressively when

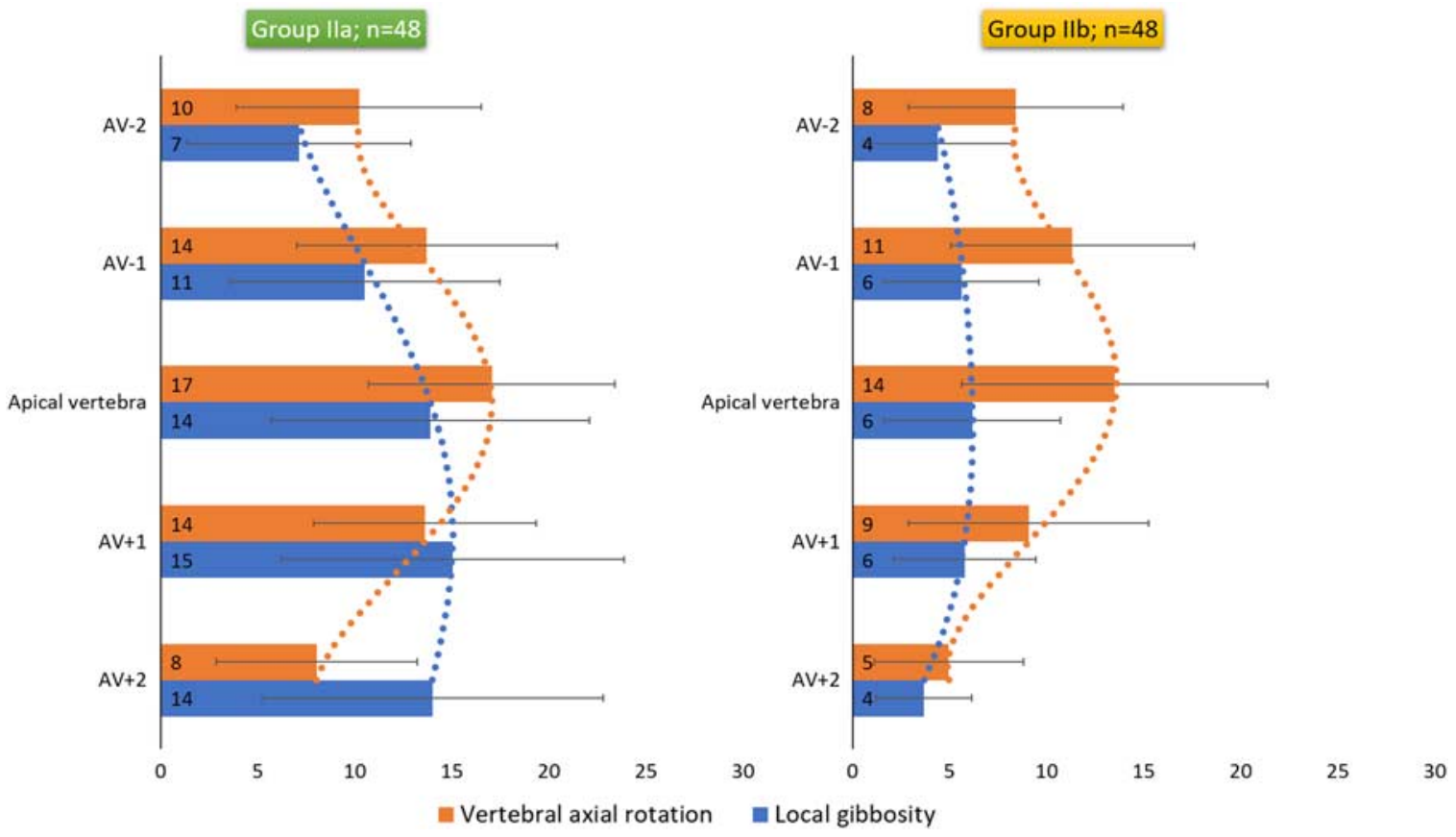

FIGURE 7. Local gibbosity and vertebral axial rotation at vertebral levels of the scoliotic segment. AV indicates apical vertebra. full color 


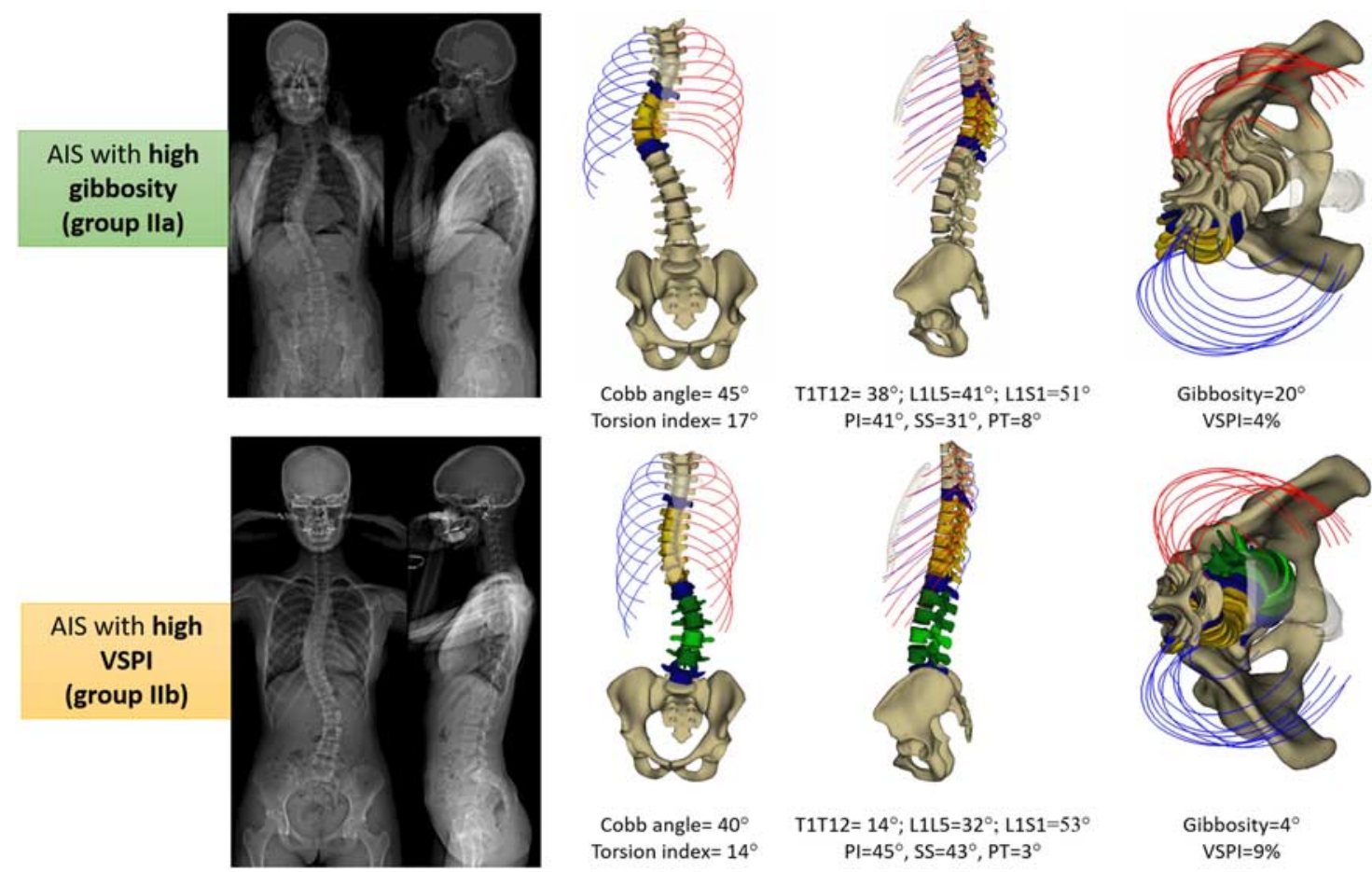

FIGURE 8. Examples of AIS subjects with high gibbosity (group Ila) and high VSPI (group Ilb). AIS indicates adolescent idiopathic scoliosis; PI, pelvic incidence; PT, pelvic tilt; SS, sacral slope; VSPI, volumetric spinal penetration index. fullc color

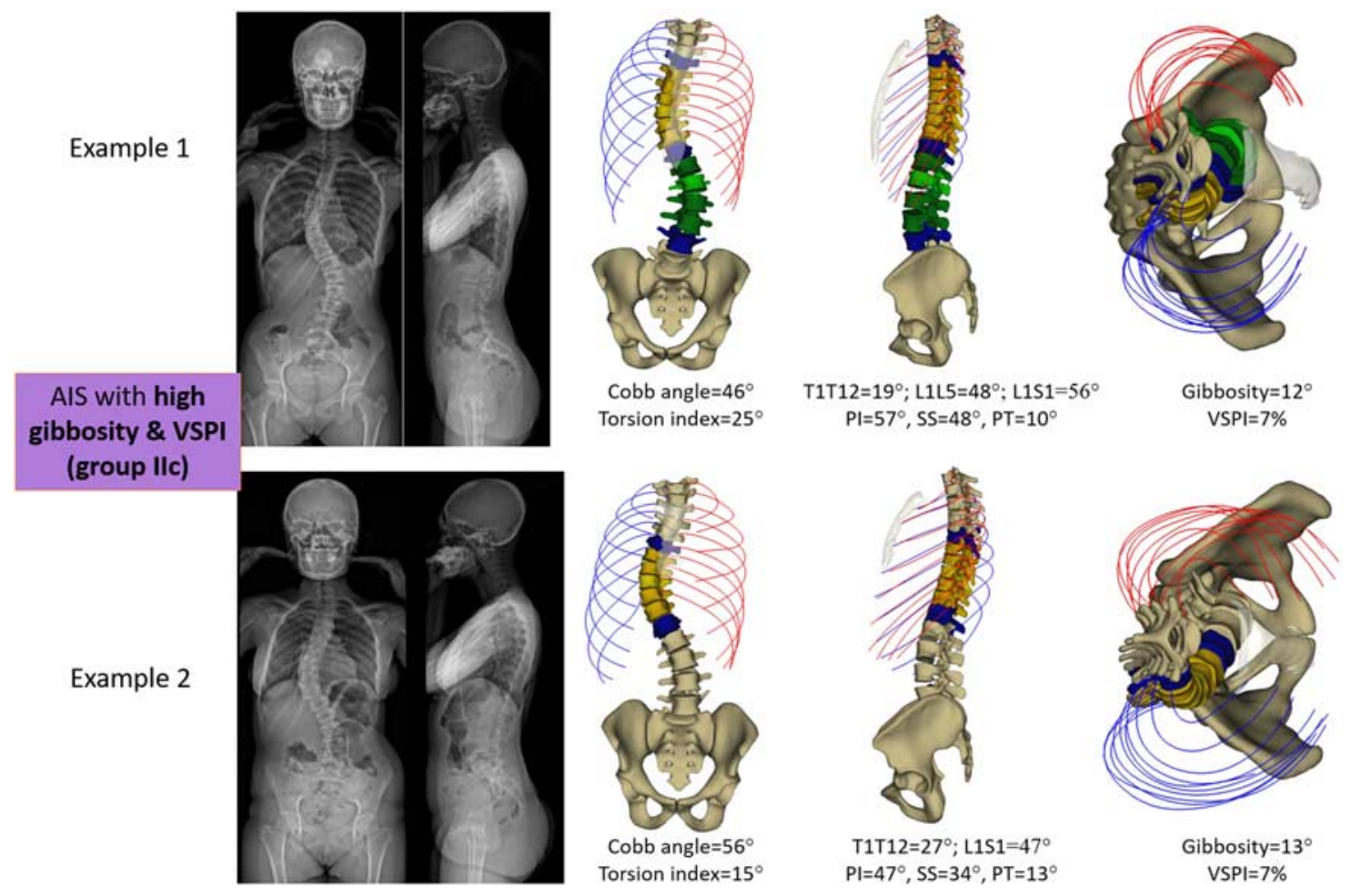

FIGURE 9. Two examples of AIS with severe rib cage deformity: presenting both high gibbosity and VSPI. AIS indicates adolescent idiopathic scoliosis; PI, pelvic incidence; PT, pelvic tilt; SS, sacral slope; VSPI, volumetric spinal penetration index. $\frac{\text { full color }}{o n l i n e}$ 
descending from the proximal to the distal segments and did not follow the axial rotation of the spine.

Subjects in group IIc showed all the characteristics presented above, with the most severe scoliotic deformity in the frontal and horizontal planes; 2 examples were displayed in Figure 9. When comparing these 2 subjects, even though they presented with a similar gibbosity and VSPI, differences existed between the 2 in the Cobb angle, TI, and sagittal alignment.

This new classification of rib cage deformity in subjects with AIS shows that subjects with high gibbosity only (IIa) are more likely to suffer from esthetic discomfort and less from respiratory impairment, while subjects with high VSPI (IIb and IIc) would be more prone to develop restrictive lung disease. Moreover, this finding highlights the question of ageing presented when assessing the progression of subjects with AIS in group IIb and IIc, who should be followed-up more closely due to the risk of developing alterations in maintaining their upright balance because of respiratory impairments. ${ }^{46}$

In conclusion, these findings are of utmost importance while assessing and planning treatment for patients with AIS. Treatment indications in groups I and IIa should follow the consensual basic principles reported in the literature, regarding bracing and surgery. However, the management of cases with high VSPI (groups IIb and IIc), for whom the primary issue relies in the potential for the degradation of respiratory function and not esthetic considerations, should focus on restoring as much kyphosis as possible. This remains hazardous with nonoperative treatments, as braces are known to aggravate thoracic hypokyphosis ${ }^{47}$ and subsequently respiratory function. As a result, surgical intervention should be preferred in subjects presenting with lower frontal Cobb angles than commonly indicated when taking the morphology of the rib cage into consideration. Thus, this classification should guide surgeons not to rely only on the magnitude of the frontal Cobb and gibbosity to assess scoliosis, but also on the amount of vertebral rotation and hypokyphosis that are related to the volume of the rib cage and spinal penetration, both of which threaten lung function in adolescents with idiopathic scoliosis. This novel 3D rib cage deformity classification along with these new surgical suggestions could have a direct impact on the treatment outcome and should prove beneficial to the patients.

\section{REFERENCES}

1. Piątek E, Kuczyński M, Ostrowska B. The effects of active selfcorrection on postural control in girls with adolescent idiopathic scoliosis: the role of an additional mental task. Int $J$ Environ Res Public Health. 2020;17:1640-1647.

2. Pratt RK, Burwell RG, Cole AA, et al. Patient and parental perception of adolescent idiopathic scoliosis before and after surgery in comparison with surface and radiographic measurements. Spine (Phila Pa 1976). 2002;27:1543-1550; discussion 1551-1552.

3. Zaina F, Pesenti F, Persani L, et al. Prevalence of idiopathic scoliosis in anorexia nervosa patients: results from a cross-sectional study. Eur Spine J. 2018;27:293-297.

4. Yagci G, Karatel M, Yakut Y. Body awareness and its relation to quality of life in individuals with idiopathic scoliosis. Percept Mot Skills. 2020;127:841-857.

5. Misterska E, Glowacki M, Latuszewska J, et al. Perception of stress level, trunk appearance, body function and mental health in females with adolescent idiopathic scoliosis treated conservatively: a longitudinal analysis. Qual Life Res. 2013;22:1633-1645.

6. Danielsson AJ, Wiklund I, Pehrsson K, et al. Health-related quality of life in patients with adolescent idiopathic scoliosis: a matched follow-up at least 20 years after treatment with brace or surgery. Eur Spine J. 2001;10:278-288.

7. Lang $\mathrm{C}$, Wang $\mathrm{R}$, Chen $\mathrm{Z}$, et al. Incidence and risk factors of cardiac abnormalities in patients with idiopathic scoliosis. World Neurosurg. 2019;125:e824-e828.

8. Verla $\mathrm{T}$, Adogwa $\mathrm{O}$, Toche $\mathrm{U}$, et al. Impact of increasing age on outcomes of spinal fusion in adult idiopathic scoliosis. World Neurosurg. 2016;87:591-597.

9. Demirel A, Pedersen PH, Eiskjær SP. Cumulative radiation exposure during current scoliosis management. Dan Med J. 2020;67:A06190366.

10. Simony A, Hansen EJ, Christensen SB, et al. Incidence of cancer in adolescent idiopathic scoliosis patients treated 25 years previously. Eur Spine J. 2016;25:3366-3370.

11. Bouloussa H, Pietton R, Vergari C, et al. Biplanar stereoradiography predicts pulmonary function tests in adolescent idiopathic scoliosis: a cross-sectional study. Eur Spine J. 2019;28:1962-1969.

12. Yaszay B, Bastrom TP, Bartley CE, et al. The effects of the threedimensional deformity of adolescent idiopathic scoliosis on pulmonary function. Eur Spine J. 2017;26:1658-1664.

13. Dreimann M, Hoffmann M, Kossow K, et al. Scoliosis and chest cage deformity measures predicting impairments in pulmonary function: a cross-sectional study of 492 patients with scoliosis to improve the early identification of patients at risk. Spine (Phila Pa 1976). 2014;39:2024-2033.

14. Negrini S, Donzelli S, Aulisa AG, et al. 2016 SOSORT guidelines: orthopaedic and rehabilitation treatment of idiopathic scoliosis during growth. Scoliosis Spinal Disord. 2018;13:1-48.

15. Roach JW, Mehlman CT, Sanders JO. Does the outcome of adolescent idiopathic scoliosis surgery justify the rising cost of the procedures? J Pediatr Orthop. 2011;31(suppl 1):S77-S80.

16. Reamy BV, Slakey JB. Adolescent idiopathic scoliosis: Review and current concepts. Am Fam Physician. 2001;64:111-116.

17. Mac-Thiong J-M, Labelle H, Charlebois M, et al. Sagittal plane analysis of the spine and pelvis in adolescent idiopathic scoliosis according to the coronal curve type. Spine (Phila Pa 1976). 2003;28:1404-1409.

18. Labaki C, Otayek J, Massaad A, et al. Is the apical vertebra the most rotated vertebra in the scoliotic curve? J Neurosurg Spine. 2019;31:873-879.

19. Dimeglio A, Canavese F. The growing spine: how spinal deformities influence normal spine and thoracic cage growth. Eur Spine J. 2012;21:64-70

20. Benameur S, Mignotte M, Destrempes F, et al. Three-dimensional biplanar reconstruction of scoliotic rib cage using the estimation of a mixture of probabilistic prior models. IEEE Trans Biomed Eng. 2005;52:1713-1728.

21. Fabris D, Costantini S. Vertebral rotation during the initial stages of scoliosis: the costovertebral interaction mechanism. Ital J Orthop Traumatol. 1988;14:59-66.

22. Aulisa AG, Guzzanti V, Perisano C, et al. Correlation between hump dimensions and curve severity in idiopathic scoliosis before and after conservative treatment. Spine (Phila Pa 1976). 2018;43:114-119.

23. Dubousset J, Wicart P, Pomero V, et al. Spinal penetration index: new three-dimensional quantified reference for lordoscoliosis and other spinal deformities. J Orthop Sci. 2003;8:41-49.

24. Johnston CE, Stephens Richards B, Sucato DJ, et al. Correlation of preoperative deformity magnitude and pulmonary function tests in adolescent idiopathic scoliosis. Spine (Phila Pa 1976). 2011;36: 1096-1102.

25. Grivas TB, Vasiliadis ES, Koufopoulos G, et al. Study of trunk asymmetry in normal children and adolescents. Scoliosis. 2006;1:1-8.

26. Lee CS, Hwang CJ, Lee SW, et al. Changes of deformity due to the position and anesthesia in adolescent idiopathic scoliosis. $J$ Spinal Disord Tech. 2010;23:377-382.

27. Aubert B, Vergari C, Ilharreborde B, et al. 3D reconstruction of rib cage geometry from biplanar radiographs using a statistical parametric model approach. Comput Methods Biomech Biomed Eng Imaging Vis. 2016;4:281-295. 
28. Jolivet E, Sandoz B, Laporte S, et al. Fast 3D reconstruction of the rib cage from biplanar radiographs. Med Biol Eng Comput. 2010;48:821-828.

29. Pietton R, Bouloussa H, Vergari C, et al. Rib cage measurement reproducibility using biplanar stereoradiographic $3 \mathrm{D}$ reconstructions in adolescent idiopathic scoliosis. J Pediatr Orthop. 2020;40:36-41.

30. Faro FD, Marks MC, Pawelek J, et al. Evaluation of a functional position for lateral radiograph acquisition in adolescent idiopathic scoliosis. Spine (Phila Pa 1976). 2004;29:2284-2289.

31. Melhem E, Assi A, El Rachkidi R, et al. EOS biplanar x-ray imaging: concept, developments, benefits, and limitations. $J$ Child Orthop. 2016;10:1-14.

32. Vergari C, Karam M, Pietton R, et al. Spine slenderness and wedging in adolescent idiopathic scoliosis and in asymptomatic population: an observational retrospective study. Eur Spine J. 2020;29:726-736.

33. Humbert L, De Guise JA, Godbout B, et al. Fast 3D reconstruction of the spine from biplanar radiography: a diagnosis tool for routine scoliosis diagnosis and research in biomechanics. Comput Methods Biomech Biomed Engin. 2009;12(S1):151-163.

34. Courvoisier A, Ilharreborde B, Constantinou B, et al. Evaluation of a three-dimensional reconstruction method of the rib cage of mild scoliotic patients. Spine Deform. 2013;1:321-327.

35. Legaye J, Duval-Beaupère G. Sagittal plane alignment of the spine and gravity a radiological and clinical evaluation. Acta Orthop Belg. 2005;71:213-220.

36. Lenke LG, Betz RR, Harms J, et al. Adolescent idiopathic scoliosis: a new classification to determine extent of spinal arthrodesis. $J$ Bone Joint Surg Am. 2001;83-A:1169-1181.

37. Abelin-Genevois K, Sassi D, Verdun S, et al. Sagittal classification in adolescent idiopathic scoliosis: original description and therapeutic implications. Eur Spine J. 2018;27:2192-2202.
38. Altaf F, Gibson A, Dannawi Z, et al. Adolescent idiopathic scoliosis. BMJ. 2013;346:f2508.

39. Wang W, Zhu Z, Zhu F, et al. Different curve pattern and other radiographical characteristics in male and female patients with adolescent idiopathic scoliosis. Spine (Phila Pa 1976). 2012;37: $1586-1592$

40. Jackson RP, Hales C, Trueman E, et al. Radiographic analysis of the sagittal alignment and balance of the spine in asymptomatic subjects. Eur Spine J. 2013;36:260-267.

41. Charles YP, Marcoul A, Schaeffer M, et al. Three-dimensional and volumetric thoracic growth in children with moderate idiopathic scoliosis compared with normal. J Pediatr Orthop Part B. 2017;26: 227-232.

42. Duval-Beaupère G, Schmidt C, Cosson P. A barycentremetric study of the sagittal shape of spine and pelvis: the conditions required for an economic standing position. Ann Biomed Eng. 1992;20:451-462.

43. Legaye J, Duval-Beaupère G, Hecquet J, et al. Pelvic incidence: a fundamental pelvic parameter for three-dimensional regulation of spinal sagittal curves. Eur Spine J. 1998;7:99-103.

44. Ilharreborde B, Dubousset J, Skalli W, et al. Spinal penetration index assessment in adolescent idiopathic scoliosis using EOS low-dose biplanar stereoradiography. Eur Spine J. 2013;22:2438-2444.

45. Takahashi S, Suzuki N, Asazuma T, et al. Factors of thoracic cage deformity that affect pulmonary function in adolescent idiopathic thoracic scoliosis. Spine (Phila Pa 1976). 2007;32:106-112.

46. Attali V, Clavel L, Rouch P, et al. Compensation of respiratoryrelated postural perturbation is achieved by maintenance of head-topelvis alignment in healthy humans. Front Physiol. 2019;10:1-10.

47. Courvoisier A, Drevelle X, Vialle R, et al. 3D analysis of brace treatment in idiopathic scoliosis. Eur Spine J. 2013;22:2449-2455. 